\title{
Management of Flabby Ridges using Liquid Supported Denture
}

\author{
Hawraz S. Abdulkareem ${ }^{1}$, Salem A. Salem ${ }^{2}$ \\ ${ }^{1}$ Department of Prosthodontic, Khanzad Teaching Center, Ministry of Health, Kurdistan Region, Erbil, Iraq, ${ }^{2}$ Department of Prosthodontic, \\ College of Dentistry, Baghdad University, Baghdad, Iraq
}

\begin{abstract}
${ }^{*}$ Corresponding author: Hawraz S. Abdulkareem, Department of Head of Prosthodontic, Khanzad Teaching Center, Ministry of Health, Kurdistan Region, Erbil, Iraq.

E-mail: gulan.center@gmail. com
\end{abstract}

Received: 15 June 2020

Accepted: 23 September 2020

Published: 30 June 2021

\section{DOI}

10.25156/ptj.v11n1y2021.

pp27-31

\section{A B S TR A C T}

The concept of conditioning edentulous ridge mucosa has gained momentum over the last several years. Frequent relining of the complete denture may be required because of soft tissue changes arising from underlining bone resorption. Patients with the maxillary flabby ridge had difficulty in tolerating hard denture, inadequate retention, and stability of a complete denture are often encountered, so the denture can be made more comfortable using soft liner. Hardening of the soft liner with time, harboring of bacteria, and debonding from denture base is a major drawback of soft lining materials. Introduction of liquid-supported dentures, to be an alternative to conventional complete denture prosthesis in cases suffered from inflamed tissues and severely resorbed edentulous ridges. A liquid supported denture provides an alternate treatment option due to its soft and flexible intaglio surface allows better distribution of masticatory load stress since in such cases. Liquid supported acrylic complete denture can be useful as a permanent solution in edentulous patients with the atrophied ridge. Liquid supported denture could be a useful alternative for soft relining materials.

Keywords: Liquid supported denture; Flabby ridges; Glycerin; Flexible tissue surface; Soft liner

\section{INTRODUCTION}

The fibrous tissue of the edentulous ridge is composed of hyperplastic mucosal tissue and loosely arranged fibrous connective tissues. Which is a superficial area of mobile soft tissue developed when hyperplastic soft tissue replaces the alveolar bone affecting the maxillary or mandibular alveolar ridges. It is frequently occurring in long-term denture wearers (Crawford and Walmsley, 2005). Furthermore, trauma from denture bases in the edentulous patient is reported to because of flabby ridges (Kelly, 2003) and found more commonly in the anterior region (Zarb et al., 1997; Carlsson, 1998; Basker et al., 2011) in the soft tissue, of these cases a great amount of metaplastic cartilage and bone are observable (Magnusson et al., 1986).

Prosthodontic treatment in these patients can be more challenging, loss of stability and inadequate retention of the dentures are major problems encountered in these patients. Because of easily distorted flabby tissue during impression taking. Options for treatment for these patients include surgery, implant overdenture, or conventional complete denture without surgical intervention, patient's state of health and need, the extent of flabby tissue, financial capacity, and skill of the dentist is the most factors that treatment modality depending on. In the most situations, surgical intervention or use of implants is not possible and conservative management is the treatment of choice. The use of elastic impression material to relieve traumatized tissue, shown that can be only a temporary treatment option. Moreover, it could easily lead to candida growth (Chase, 1961).

The denture construction for a flabby edentulous ridge condition should be able to withstand masticatory occlusal load, and have a flexible tissue surface in order to reduce stress concentration and trauma of the underlying tissues (Dammani et al., 2007). Hence, liquid supported denture can be a solution to this problem. This case reports liquid supported denture was planned for a patient with a complete edentulous maxillary arch with a flabby edentulous ridge in the anterior region of maxilla, opposing mandibular complete denture for the lower arch.

Liquid supported denture may be indicated in severely resorbed maxillary and mandibular ridges, inflamed or flabby tissues, vesiculobullous lesions, and patients with systemic disorders like diabetes. The advantage includes preservation of residual ridge by the distribution of masticatory load over the larger surface area as possible, improved patient tolerance because of great comfort due to smooth flexible surfaces, prevents chronic soreness which occurs from rigid denture surface and has a cushioning effect thus helps condition underlining tissues. 
Precaution should be taken during the construction of this type of dentures, the thickness of the denture base should be $2 \mathrm{~mm}$ and the seal should be perfect and should be checked for microleakage.

\section{CASE REPORT}

A 65-year-old male reported to Khanzad Teaching Center for complete denture fabrication. A 65-year-old male patient was wearing maxillary complete denture for 2 years reported to Khanzad Teaching Center asking for new complete denture fabrication. The chief complaint is the poor fit of the maxillary complete denture and felt loose during eating. According to the intraoral examination, a complete edentulous maxillary arch with fibrous tissue was existing in the anterior region of the arch [Figure 1]. Keeping the various challenges associated with the case, clinical steps, and treatment plan was carefully modified to suit the best of the patient's needs. Maxillary complete denture (liquid supported) opposing a mandibular conventional complete denture were constructed primary impressions were made with impression compound (Hoffman, Germany). The fibrous tissue is marked in the mouth by indelible pencils and transferred to the primary cast [Figure 2]. On the primary maxillary cast the marked flabby ridge area covered with double sheet wax, perforated special tray was made using cold cured acrylic (Meliodent, Kulzer), and with two handles posteriorly and other in the midline in the hard palate region [Figure 3]. Border molding was performed using a green stick impression compound (Hoffman, Germany) and zinc oxide eugenol (SS WHITE) used as a final impression material. Thus, the flabby tissue was recorded in the rest position. For the mandibular impressions, the conventional method was used [Figure 4]. Centric occlusal relationship recorded then transferred to the master cast and the cast mounted. Teeth were set and the try-in procedure of the waxed denture was done subsequently.

Steps in fabricating a liquid supported denture:

1. Vacuum heat pressed of $1 \mathrm{~mm}$ thickness polyethylene sheet (COPYPLAST ${ }^{\circledR}$, Scheu dental Germany), [Figure 5] was vacuumed on the master cast before packing. Code no. 172, refer to programed (heating temperature $\left[200^{\circ} \mathrm{C}\right]$, heating time $[55 \mathrm{~s}]$, amount of bar pressure [5.0]) required for each type sheet refer to Scheu dental company that installed inside vacuum machine [Figure 6]

2. The sheet was made $2 \mathrm{~mm}$ short of the sulcus and was not extended in the Posterior Palatal Seal area. This sheet was incorporated in the denture at the time of packing [Figure 7]. In such a way, the inner surface of the denture is made from a polyethylene sheet

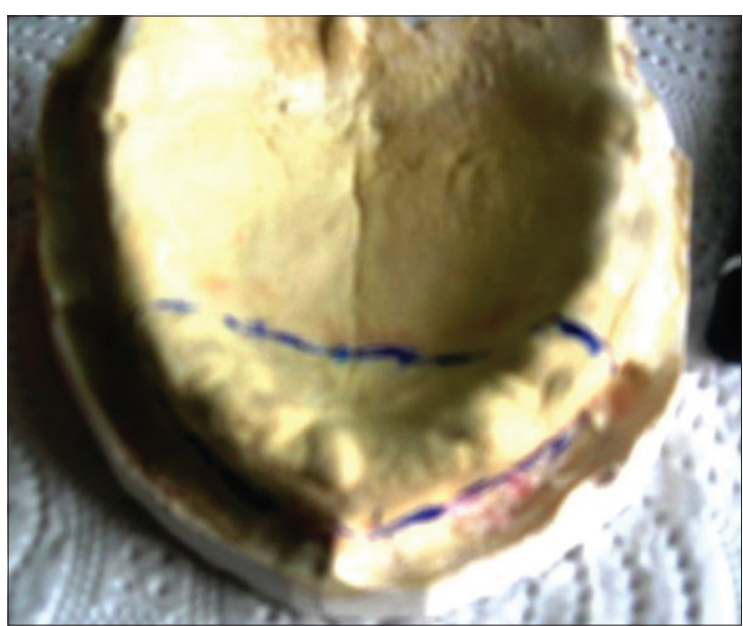

Figure 1: Intra-oral view of maxillary arch

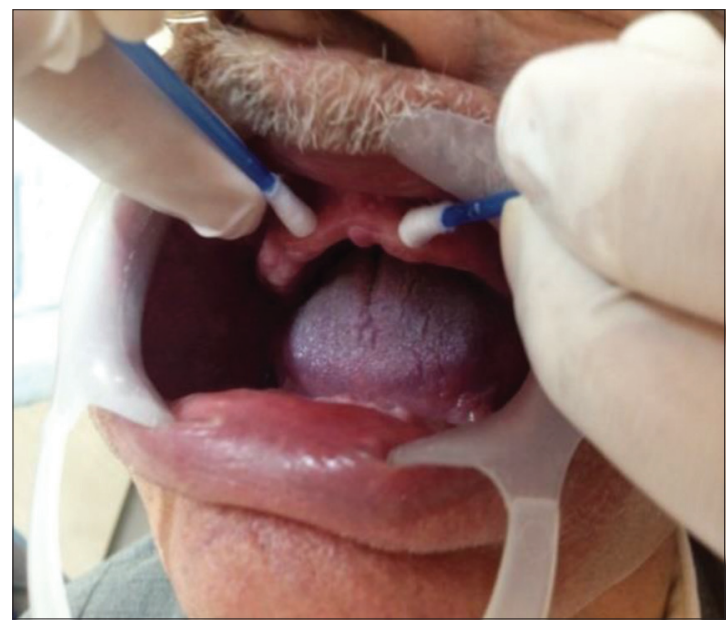

Figure 2: Demarcation of flabby area

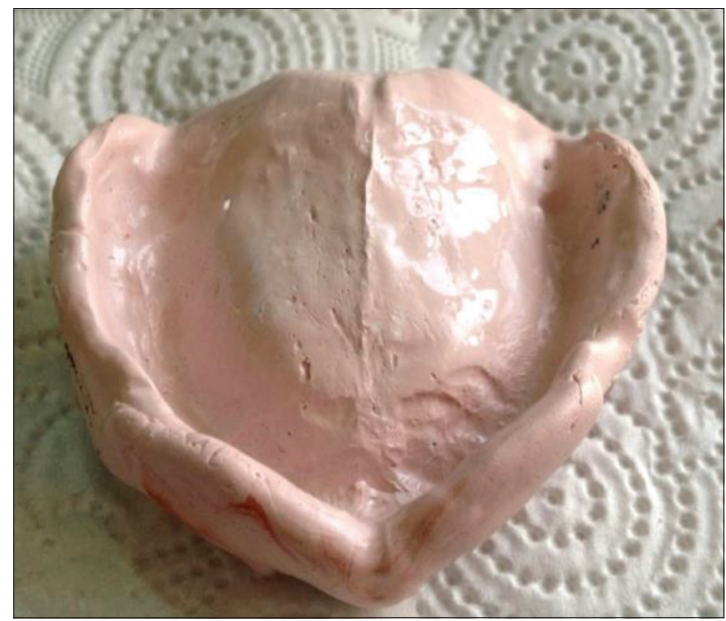

Figure 3: Special tray for maxillary primary

3. Hot curing acrylic (Meliodent, Kulzer) used for the construction of the conventional upper and lower complete denture

4. The upper complete denture that lined with a polyethylene sheet and lower conventional complete 
denture is inserted to the patients' mouth after making the occlusal adjustments

5. The patient was given a recall appointment after 2 weeks to convert the denture into a liquid supported denture. This was done for checking the comfort level

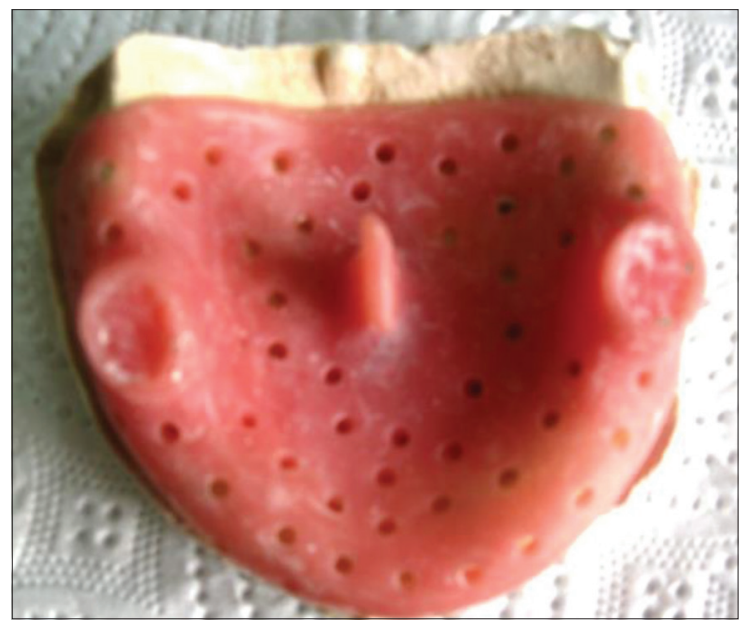

Figure 4: Final impression of maxillary arch cast

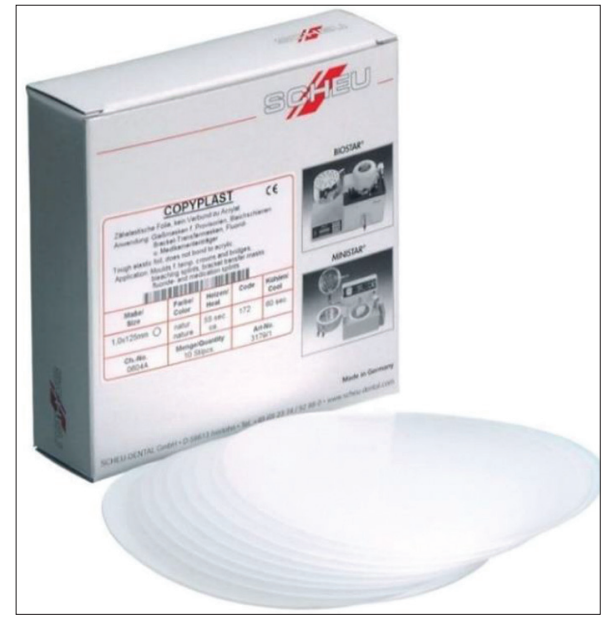

Figure 5: Copyplast sheet (Scheu Dental, Germany)

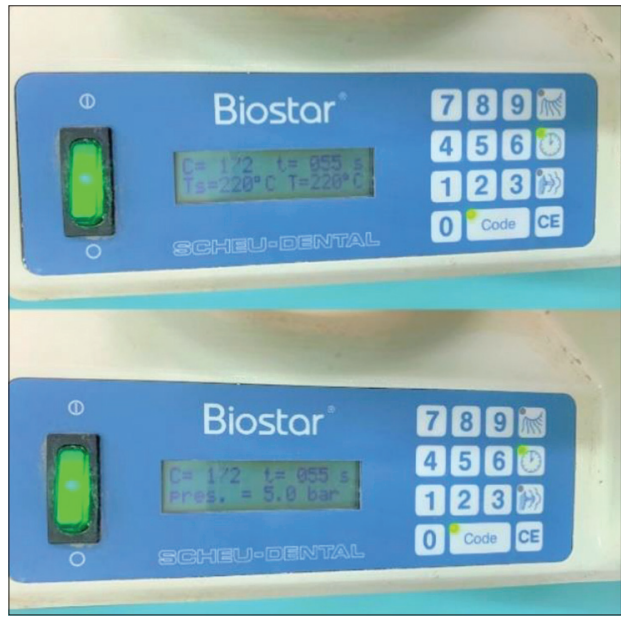

Figure 6: Code 172 Biostar parameter of the patient to the polyethylene sheet placed inside the tissue side of the upper denture

6. At the recall appointment (after 2 weeks), the $1 \mathrm{~mm}$ thick polyethylene sheet was used as a spacer removed from the denture. Because of the removal of the biostar sheet boundaries were formed all along the denture borders. These crevices were helpful as a guide in the final placement of a 0.5 polyethylene sheet. (COPYPLAST ${ }^{\circledR}$, Scheu Dental Germany)

7. A polyvinyl silicone impression made for the tissue surface of the denture, which used as a putty index, after removal of $1.0 \mathrm{~mm}$ sheet polyethylene and the stone cast was made using (GC fuji rock ep) of it to record the exact junction of the sheet to the denture [Figure 8]. After that $0.5 \mathrm{~mm}$ thick polyethylene sheet. COPYPLAST $^{\circledR}$, Scheu dental Germany was vacuum pressed on the cast at which was used in place of $1 \mathrm{~mm}$ thick polyethylene sheet creating a $0.5 \mathrm{~mm}$ space. The code no.132 for the sheet refers to programed (heating

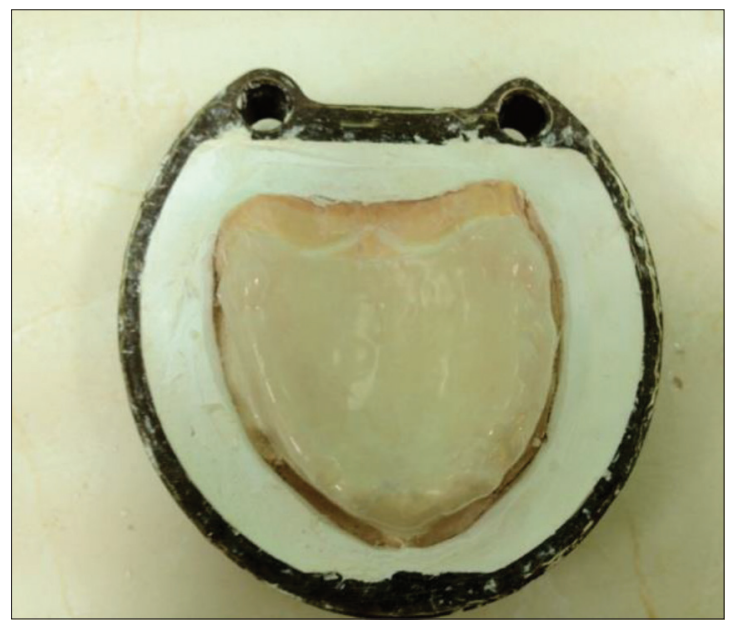

Figure 7: $1 \mathrm{~mm}$ thick sheet placed on the invested master cast before packing

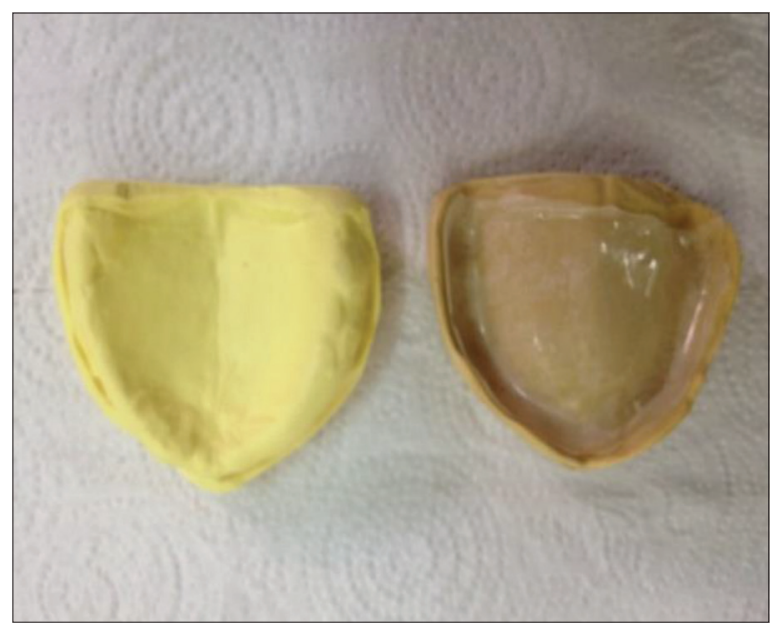

Figure 8: Stone cast poured from putty impression to make the exact junction of $(0.5 \mathrm{~mm})$ thick poly ethylene sheet 
temperature $\left[200^{\circ} \mathrm{C}\right]$, heating time $[35 \mathrm{~s}]$, amount of bar pressure 4.8) as shown in Figure 9

8. Using the putty index as a guide for polyethylene sheet cutting, then the borders of the $0.5 \mathrm{~mm}$ thick sheet placed in the crevice formed inside the inner surface of the upper denture due to the removal of $1 \mathrm{~mm}$ thick polyethylene sheet

9. Cyanoacrylate adhesive liquid and cold-cure acrylic resin used to seal the borders and prevent the escape of liquid

10. Commercially available glycerin was used to fill the space had been created due to the replacement of a $1 \mathrm{~mm}$ thick sheet with a $0.5 \mathrm{~mm}$ thick sheet. This is done by making two holes in the buccal flanges of the denture and injection of glycerin through the holes and simultaneously checking the vertical dimensions of occlusion. The holes were sealed using self-cure acrylic resin. Finally, the upper liquid supported denture that lined with 0.5 polyethylene sheet, and the glycerin act as a liquid barrier between the acrylic denture base and polyethylene sheet [Figures 10 and 11].

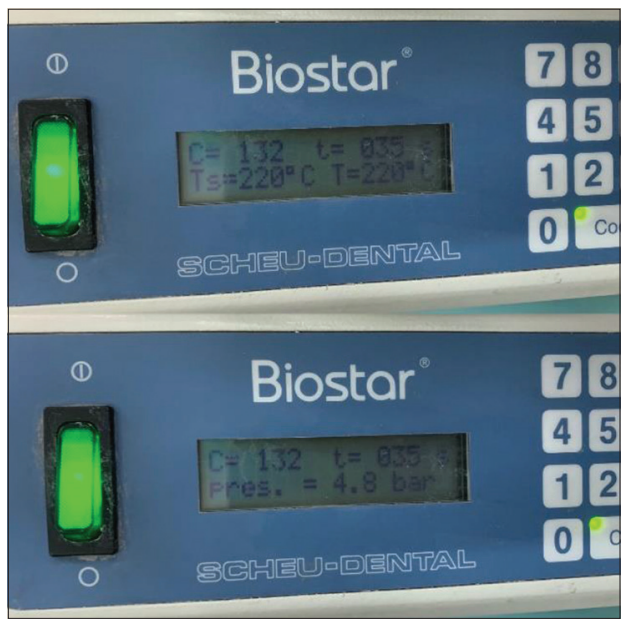

Figure 9: Code 132 Biostar parameter

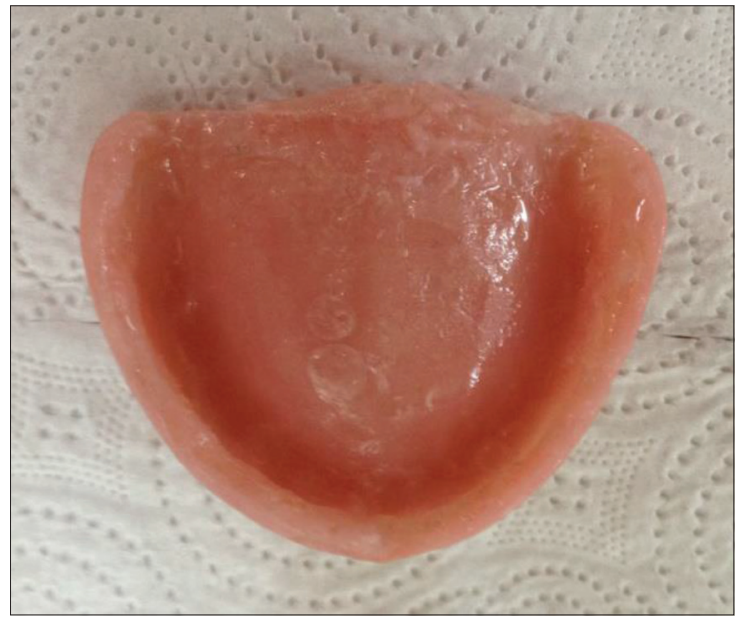

Figure 10: Final maxillary denture with $0.5 \mathrm{~mm}$ poly ethylene

\section{DISCUSSION}

The presence of flabby tissue in the anterior portion of the maxillary arch is considered as a major problem associated with this case which is solved by modification in the impression procedures and by fabrication of upper liquid supported complete denture.

The theory of this is based on that when the force applied on the denture is absent; the base assumes its reshaped form that is the one during processing. During masticatory functional load, the base adapts to the modified form of underlining mucosa due to hydrodynamics behaviors of the liquid leading to improvement in support, retention, and stability. Thus, the maximum stress distribution of masticatory forces over a larger area which reduces tissue overloading. Prevention of soreness and increased comfort level for the patient is other advantages of the liquid supported complete maxillary denture (Davidson and Boere, 1990; Boere et al., 1990).

In this case, polyethylene thermoplastic clear sheet, Biostar sheet code no. 172 and Biostar vacuum forming machine, Scheu Dental Germany used because of its softness, flexibility, and biocompatibility.

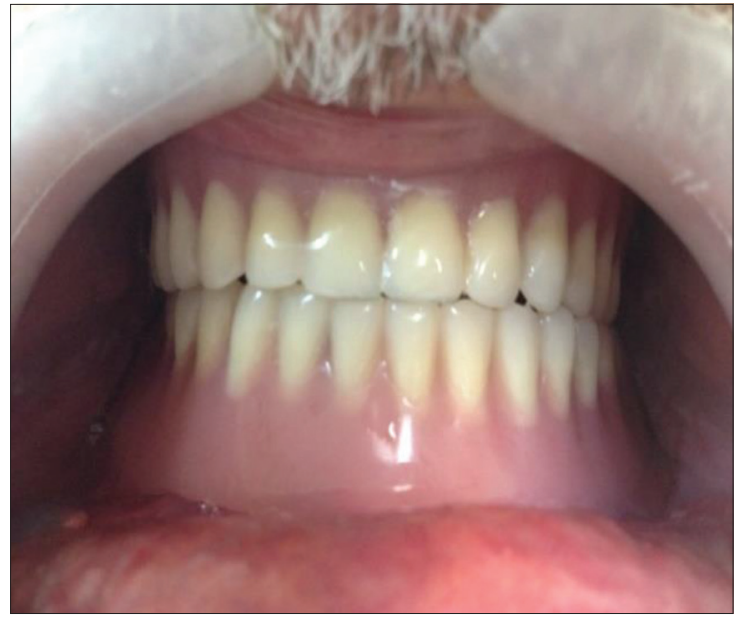

Figure 11: Final denture in the mouth

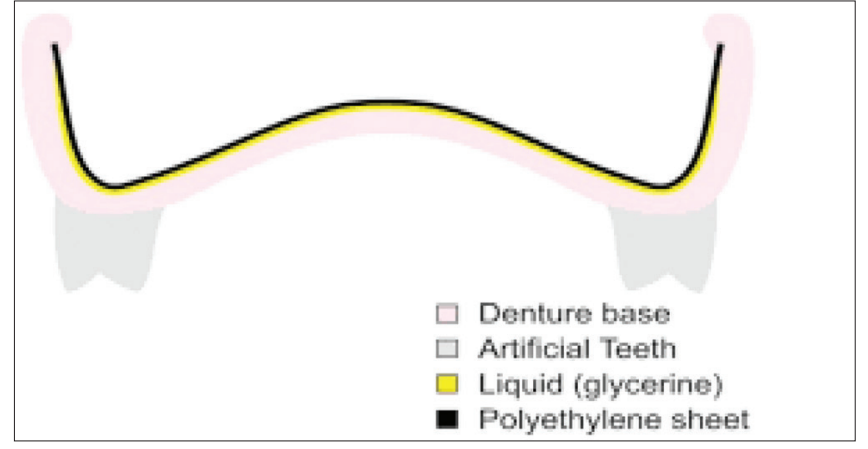

Figure 12: Illustration of liquid supported denture 
The choice of glycerin as a liquid between the hard denture base and soft ethylene sheet because it is clear, viscous, and biocompatible and has been used as a vehicle in liquid medications.

\section{CONCLUSION}

The use of liquid supported denture can improve the patient's comfort due to Harmonious distribution of occlusal forces of mastication and adds series of attributes to the conventional complete denture to fulfill the DeVan's dictum "Preservation of That What Remains rather than Meticulous Replacement of What Has Been Lost" (Atwood, 1963).

\section{REFERENCES}

Atwood, D. A. 1963. Postextraction changes in the adult mandible as illustrated by microradiographs of midsagittal sections and serial cephalometric roentgenograms. J. Prosthetic Dent. 13: 810-824.

Basker, R. M., J. C. Davenport and J. M. Thomason. 2011. Prosthetic Treatment of the Edentulous Patient. John Wiley and Sons,
United States.

Boere, G., H. De Koomen and C. L. Davidson. 1990. Liquidsupported Dentures. Part II: Clinical Study, a Preliminary Report. J. Prosthetic Dent. 63: 434-436.

Carlsson, G. E. 1998. Clinical morbidity and sequelae of treatment with complete dentures. J. Prosthetic Dent. 79: 17-23.

Chase, W. W. 1961. Tissue conditioning utilizing dynamic adaptive stress. J. Prosthetic Dent. 11: 804-815.

Crawford, R. and A. Walmsley. 2005. A review of prosthodontic management of fibrous ridges. Br. Dent. J. 199: 715-719.

Dammani, B., S. Shingote, S. Athavale and D. Kakade. 2007. Liquidsupported denture: a gentle option. J. Indian Prosthod. Soc. 7: 35.

Davidson, C. L. and G. Boere. 1990. Liquid-supported dentures. Part I: Theoretical and technical considerations. J. Prosthetic Dent. 63: 303-306.

Kelly, E. 2003. Changes caused by a mandibular removable partial denture opposing a maxillary complete denture. J. Prosthetic Dent. 90: 213-219.

Magnusson, B., H. Engström and K. Kahnberg. 1986. Metaplastic formation of bone and chondroid in flabby ridges. Br. J. Oral Maxillofac. Surg. 24: 300-305.

Zarb, G., C. Bolender, J. Hickey and G. Carlsson. 1997. Boucher's Prosthodontic Treatment Foredentulous Patients. Mosby, St. Louis, MO. 